\title{
Evaluation of Fruit Shape Variations in Spanish Eggplants using an Image Analysis Software
}

\author{
M. Plazas, S. Vilanova, M. Hurtado, P. Gramazio, I. Andújar, F.J. Herraiz and J. Prohens*
}

\author{
Instituto de Conservación y Mejora de la Agrodiversidad Valenciana \\ Universidad Politécnica de Valencia \\ Valencia, Spain
}

\begin{abstract}
Traditional descriptors for characterization of fruit shape of eggplant (Solanum melongena L.) provide limited information and do not allow a detailed characterization of this complex trait. New image analysis software tools like Tomato Analyzer, allow obtaining quantitative and objective data for a large number of fruit shape parameters. The Tomato Analyzer software tool was used for the evaluation of fruit shape in a collection of traditional varieties of eggplant from four varietal groups (Round, Semi-long, Egg Shaped, and Long). A total of 26 fruit shape parameters were obtained using the Tomato Analyzer software. Significant differences were found among varieties for all traits, except for shoulder height. In addition, considerable differences were identified among varietal groups for many parameters. Values for broad-sense heritability were high for most of the traits. The principal components analysis clearly separated the four varietal groups. Discriminant analysis allowed the correct classification to their actual variety of almost $60 \%$ of the individual fruits. The wide variation observed and high values for heritability for most fruit shape parameters indicated that the image analysis software tools like Tomato Analyzer are of great utility for the phenotypic characterization of fruit shape in eggplant germplasm. This has important implications for selection and breeding for this important trait in eggplant.
\end{abstract}

Keywords: Breeding, germplasm, Image Analysis software, Solanum melongena, Tomato Analyzer

\section{INTRODUCTION}

Fruit shape is a trait of great importance for breeding of eggplant (Solanum melongena L.) (Daunay, 2008). Eggplant cultivar groups are commonly classified according to their fruit shape (Nunome et al., 2001; Daunay, 2008). Within the eggplant germplasm, the main cultivar groups recognized according to the fruit shape are Round, Semi-Long, and Long (Nunome et al., 2001; Prohens et al., 2005; Tümbilen et al., 2011). Spain is a secondary center of diversity for eggplant (Hurtado et al., 2012), and the cultivar group Listada de Gandía is also recognized as having a different fruit shape (Muñoz-Falcón et al., 2008). Each of these fruit shape groups is genetically heterogeneous (Prohens et al., 2005; Muñoz-Falcón et al., 2008), and therefore, there are ample opportunities for selection within each varietal group.

\footnotetext{
* Corresponding author: jprohens@btc.upv.es
} 
Characterization of fruit shape in eggplant has generally been based on simple traits manually measured, like fruit length or width (IBPGR, 1990; Nunome et al., 2001; Doganlar et al., 2002; Polignano et al., 2010). Although these traits are easily measured, they do not allow a precise characterization of fruit shape. In this respect, fruit shape characterization is very important for different objectives, like the description of cultivars, germplasm accessions, and selection and breeding (Costa et al., 2011).

Recently, an image analysis software denominated Tomato Analyzer has been developed for the analysis of fruit shape of tomato (Solanum lycopersicum L.) fruits (Brewer et al., 2006; Gonzalo \& van der Knaap, 2008; Rodríguez et al., 2010). Tomato Analyzer allows measuring a large number of fruit shape parameters from scanned images of fruits that have been longitudinally cut. Although it was originally designed for measuring fruit shape of tomato, it has proved the usefulness of studying the fruit shape in other species (Brewer et al., 2006; Blas et al., 2012). A first use in eggplant has been made by Prohens et al. (2012) for measuring the fruit shape in interspecific families between $S$. melongena and the related species $S$. aethiopicum (scarlet eggplant), but no studies have been performed up to now for the characterization of fruit shape in a germplasm collection of eggplant.

This paper presents the results obtained in the characterization of fruit shape using Tomato Analyzer in a group of varieties of Spanish eggplants. This will allow obtaining detailed data on fruit shape on a number of eggplant accessions differing in fruit shape. The information of the present study will be of interest to evaluate the utility of Tomato Analyzer for fruit shape characterization in eggplant, as well as for the selection and breeding for fruit shape in this crop.

\section{MATERIALS AND METHODS}

\section{Plant material and growing conditions}

A total of 21 Spanish accessions of eggplant from the germplasm bank of the Universitat Politècnica de València were used. The accessions correspond to Round (4 accessions), Listada de Gandía (striped type; 7 accessions), Semi-Long (4 accessions), and Long (6 accessions) cultivar groups. Accessions were grown in an open air field plot in Carcaixent (Valencia, Spain) during the summer season. The standard horticultural practices for eggplant production in the area of Valencia were followed (Baixauli, 2001). Plants were irrigated and fertilized using a drip irrigation system. Phytosanitary treatments were performed when necessary.

\section{Fruit shape characterization}

A random sample of 20 fruits of each accession was harvested when commercially mature. Individual fruits were weighted, and the fruit length and width were manually measured following the common protocols for standard characterization (IBPGR, 1990). Subsequently, longitudinal sections of the fruits were scanned and the images were uploaded and analyzed morphometrically for 23 traits using Tomato Analyzer 3.0 software (Rodríguez et al., 2010). A list of the traits measured is presented in Table 1. 


\section{Data analysis}

For each trait, an analysis of variance was performed and statistical significance among accessions and cultivar groups was evaluated. Broad sense heritability $\left(\mathrm{H}^{2}\right)$ was estimated for each trait from the estimated genotypic and phenotypic variances (Wricke \& Weber, 1986). A principal components analysis (PCA) was performed using the average values of each accession and Euclidean distances among accessions. Discriminant analysis was used to study the correct classification of individual fruits to their actual accession.

\section{RESULTS AND DISCUSSION}

\section{Differences among accessions}

Highly significant $(\mathrm{P}<0.001)$ differences have been found among accessions for 24 out of the 26 traits studied (Table 1). For Proximal Eccentricity, differences were significant $(\mathrm{P}<0.05)$, while for Shoulders Height they were not significant $(\mathrm{P}>0.05)$. This results reveal that, as occurs for other morphological traits and for molecular markers (Prohens et al., 2005; Polignano et al., 2010., Muñoz-Falcón et al., 2011; Tümbilen et al., 2011; Hurtado et al., 2012; Vilanova et al., 2012), a wide diversity exists within the Spanish eggplant germplasm for fruit shape. This was expected, as Spain is a secondary center of diversity for eggplant (Hurtado et al., 2012).

Table 1. Mean values, significance among accessions and among cultivar groups, and broad-sense heritability $\left(\mathrm{H}^{2}\right)$ for the fruit shape traits studied. (Full description of traits can be consulted in Rodríguez et al. (2010)).

\begin{tabular}{|c|c|c|c|c|}
\hline Trait & Mean & $\begin{array}{c}\text { Differences } \\
\text { among } \\
\text { accessions }^{\text {a }}\end{array}$ & $\begin{array}{l}\text { Differences among } \\
\text { cultivar groups }^{\mathrm{a}}\end{array}$ & $\mathbf{H}^{2}$ \\
\hline Weight (g) & 232 & *** & ns & 0.28 \\
\hline Fruit Width $(\mathrm{cm})$ & 6.71 & $* * *$ & $* * *$ & 0.66 \\
\hline Fruit Length (cm) & 15.6 & $* * *$ & $* * *$ & 0.73 \\
\hline Perimeter $(\mathrm{cm})$ & 28.3 & $* * *$ & $* * *$ & 0.58 \\
\hline Area $\left(\mathrm{cm}^{2}\right)$ & 36.8 & $* * *$ & $* *$ & 0.29 \\
\hline Width at Mid-Height (cm) & 4.30 & $* * *$ & $* * *$ & 0.72 \\
\hline Maximum Width (cm) & 4.99 & $* * *$ & $*$ & 0.44 \\
\hline Height at Mid-Width (cm) & 10.1 & $* * *$ & $* * *$ & 0.66 \\
\hline Maximum Height (cm) & 10.5 & $* * *$ & $* * *$ & 0.70 \\
\hline Fruit Shape Index External 1 & 2.27 & $* * *$ & $* * *$ & 0.78 \\
\hline Fruit Shape Index External 2 & 2.75 & $* * *$ & $* * *$ & 0.85 \\
\hline Proximal Fruit Blockiness & 0.66 & $* * *$ & $* * *$ & 0.54 \\
\hline Distal fruit Blockiness & 0.89 & $* * *$ & $* * *$ & 0.74 \\
\hline Fruit Shape Triangle & 0.76 & $* * *$ & ns & 0.34 \\
\hline Forma Ellipsoid & 0.62 & $* * *$ & $* * *$ & 0.81 \\
\hline Circular & 0.82 & $* * *$ & $* * *$ & 0.70 \\
\hline Rectangular & 0.47 & $* * *$ & $*$ & 0.26 \\
\hline Shoulder Height & 0.0054 & ns & ns & 0.01 \\
\hline Obovoid & 0.30 & $* * *$ & $* * *$ & 0.65 \\
\hline Ovoid & 0.0049 & $* * *$ & $\mathrm{~ns}$ & 0.53 \\
\hline Eccentricity & 0.77 & $* * *$ & ns & 0.13 \\
\hline Proximal Eccentricity & 0.90 & $*$ & $\mathrm{~ns}$ & 0.04 \\
\hline Distal Eccentricity & 0.90 & $* * *$ & $* * *$ & 0.19 \\
\hline Fruit Shape Index Internal & 2.76 & $* * *$ & $* * *$ & 0.85 \\
\hline Eccentricity Area Index & 0.44 & $* * *$ & $* * *$ & 0.64 \\
\hline Slender & 24.6 & $* * *$ & $* * *$ & 0.83 \\
\hline
\end{tabular}


Although the study of the fruit shape of eggplant has been reported in several works, (Nunome et al., 2001; Doganlar et al., 2002; Prohens et al., 2005; Tümbilen et al., 2011), this is the first study in which the diversity of fruit shape in a collection of eggplant germplasm is studied in detail using an image analysis software. Results show that, as in tomato (Gonzalo \& van der Knaap, 2008; Gonzalo et al., 2009; Mazzucato et al., 2010; Rodríguez et al., 2011), Tomato Analyzer software is a very useful tool for characterization of fruit shape in eggplant.

\section{Differences among cultivar groups}

Important differences have also been found among the four cultivar groups for fruit shape traits (Table 1). Cultivar groups in eggplant are differentiated according to fruit shape (Nunome et al., 2001; Prohens et al., 2005; Daunay, 2008; Tümbilen et al., 2011), and therefore differences among cultivar groups were expected. With this respect, highly significant $(\mathrm{P}<0.001)$ differences among cultivar groups for 17 traits, and significant $(\mathrm{P}<0.01$ or $\mathrm{P}<0.05$ ) differences for three other traits were found. However, for six traits (weight, fruit shape triangle, shoulder height, ovoid, eccentricity, and proximal eccentricity) no significant differences were found among cultivar groups (Table 1).

\section{Heritability}

Broad-sense heritability $\left(\mathrm{H}^{2}\right)$ ranged between 0.01 for shoulder height and 0.85 for fruit shape index internal (Table 1). For ten traits, the heritability values were high $\left(\mathrm{H}^{2} \geq 0.70\right)$, indicating that selection for fruit shape among accessions will be very efficient (Wricke \& Weber, 1986). These results are quite different from those reported by Prohens et al. (2012) in interspecific families between S. melongena and S. aethiopicum, in which the heritability values were comparatively much lower. The low values for the heritability were attributed to the small fruit size in the segregating generations, which resulted in a low genotypic diversity. However, fruit size in intraspecific families of $S$. melongena is not depressed (Rodríguez-Burruezo et al., 2008), indicating that high heritability values can be obtained for fruit shape traits in segregating generations of S. melongena.

\section{Multivariate analyses}

Principal components analysis (PCA) shows that the first and second principal components account for $64.3 \%$ and $13.1 \%$ of the total variation, respectively (Fig. 1). The first component is positively correlated with traits related to fruit width and round shape, and negatively with traits related to elongated shape. The second component is positively correlated with fruit size and negatively with triangular and ovoid fruit shape.

Representation of accessions in the PCA graph shows that the four varietal groups are plotted in different areas of the graph especially with respect to the first component. In this way, the Long and Semi-Long accessions present negative values for this first component, while the Round and Listada de Gandía accessions present positive values. The results showed that PCA analysis of fruit shape separates the different cultivars groups, as in the case of using standardized descriptors for morphological description (Prohens et al., 2005).

Discriminant analysis showed that, by using the 26 studied traits, $57.14 \%$ of the individual fruits studied are correctly classified to their actual accession (Table 2). In particular, for the Round and Long types, the percentages of correct classification are very high $(73.75 \%$ and $66.67 \%$, respectively). Taking into account the 21 accessions studied, since some of them are 
morphologically and genetically very similar (Prohens et al., 2005; Muñoz-Falcón et al., 2008), percentages of correct classification can be considered as very high.

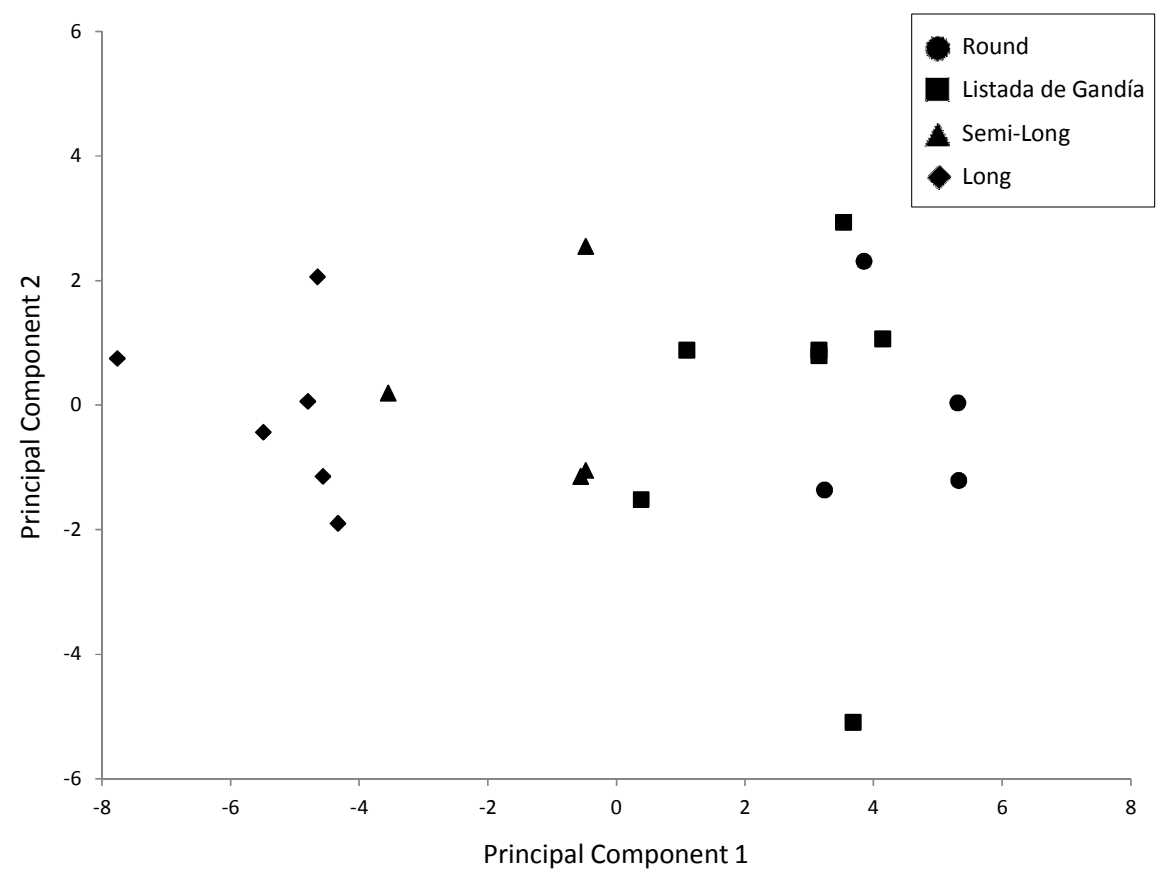

Fig. 1. Relationships among the eggplant accessions studied based on 26 fruit shape traits, according to the first ( $\mathrm{X}$-axis, accounts for $64.3 \%$ of the total variation) and second (Y-axis, accounts for $13.1 \%$ of the total variation) principal components.

Table 2.Percentage of individual fruits of Spanish eggplants correctly and incorrectly classified to their actual accession and to other accessions, according to multivariate discriminant analysis.

\begin{tabular}{lcc}
\hline Cultivar group & Correctly classified (\%) & Incorrectly classified (\%) \\
\hline Round & 73.75 & 26.25 \\
Listada de Gandía & 48.57 & 51.43 \\
Semi-Long & 41.25 & 58.75 \\
Long & 66.67 & 33.33 \\
Total & 57.14 & 42.86 \\
\hline
\end{tabular}

\section{CONCLUSIONS}

The image analysis software, Tomato Analyzer, has been of great utility for the detailed characterization of fruit shape diversity in eggplant in a collection of Spanish accessions. A wide diversity had been found among accessions as well as among cultivar groups. The high values of heritability for many of the fruit shape traits studied indicate that selection using 
Tomato Analyzer characterization data was highly efficient. PCA analysis showed that different varietal groups were separated according to fruit shape traits, although considerable diversity exists within each group. Discriminant analysis showed that the percentage of correctly classified fruits to their actual accession was high. Overall, the results indicated that Tomato Analyzer software was a powerful tool for eggplant fruit shape characterization and selection.

\section{ACKNOWLEDGEMENT}

This research has been funded by Ministerio de Economía y Competitividad (grants AGL2009-07257 and AGL2012-34213 to J. Prohens), and by Universitat Politècnica de València (grant Primeros Proyectos de Investigación to S. Vilanova). Authors are grateful to Dr. F. Nuez for allowing access to the eggplant experimental fields of the project "Protection of Valencian cultivars of vegetables" (funded by Fundación Agroalimed), and from which the fruits used here were harvested.

\section{REFERENCES}

Baixauli, C. (2001). Berenjena. pp. 104-108. In: Nuez, F. and Llácer, G. (Ed.) La horticultura española. Ediciones de Horticultura, Reus, Spain.

Blas, A.L., Yu, Q., Veatch, O.J., Paull, R.E., Moore, P.H. and Ming, R. (2012). Genetic mapping of quantitative trait loci controlling fruit size and shape in papaya. Mol. Breed. 29, 457-466.

Brewer, M.T., Lang, L., Fujimura, K., Dujmovic, N., Gray, S. and van der Knaap, E. (2006). Development of a controlled vocabulary and software application to analyse fruit shape variation in tomato and other plant species. Plant Physiol. 141, 15-25.

Costa, C., Antonucci, F., Pallottino, F., Aguzzi, J., Sun, D.W. and Menesatti, P. (2011). Shape analysis of agricultural products: a review of recent research advances and potential application to computer vision. Food Bioprocess Technol. 4, 673-692.

Daunay, M.C. (2008). Eggplant. pp. 163-220. In: Prohens, J. and Nuez, F. (Ed.) Handbook of plant breeding: Vegetables II, Springer, New York, USA.

Doganlar, S., Frary, A., Daunay, M.C., Lester, R.N. and Tanksley, S.D. (2002). Conservation of gene function in the Solanaceae as revealed by comparative mapping of domestication traits in eggplant. Genetics. 161, 1713-1726.

Gonzalo, M.J. and van der Knaap, E. (2008). A comparative analysis into the genetic bases of morphology in tomato varieties exhibiting elongated fruit shape. Theor Appl. Genet. 116, 647-656.

Gonzalo, M.J., Brewer, M.T., Anderson, C., Sullivan, D., Gray, S. and van der Knaap, E. (2009). Tomato fruit shape analysis using morphometric and morphology attributes implemented in Tomato Analyzer software program. J. Amer. Soc. Hort. Sci. 134, 77-87. 
Hurtado, M., Vilanova, S., Plazas, M., Gramazio, P., Fonseka, H.H., Fonseka, R. and Prohens, J. (2012). Diversity and relationships of eggplants from three geographically distant secondary centers of diversity. PLoS ONE 7, e41748.

IBPGR. (1990). Descriptors for eggplant. International Board for Plant Genetic Resources, Rome, Italy.

Mazzucato, A., Ficcadenti, N., Caioni, M., Mosconi, P., Piccini, E., Sanampudi, V.R.R., Sestili, S. and Ferrari, V. (2010). Genetic diversity and distinctiveness in tomato (Solanum lycopersicum L.) landraces: the Italian case study of 'A pera Abruzzese'. Sci. Hort. 125, 5562.

Muñoz-Falcón, J.E., Prohens, J., Vilanova, S. and Nuez, F. (2008). Characterization, diversity, and relationships of the Spanish striped (Listada) eggplants: a model for the enhancement and protection of heirlooms. Euphytica 164, 405-419.

Muñoz-Falcón, J.E., Vilanova, S., Plazas, M. and Prohens, J. (2011). Diversity, relationships and fingerprinting of the Listada de Gandía eggplant landrace using genomic SSRs and ESTSSRs. Sci. Hort. 129, 238-246.

Nunome, T., Ishiguro, K., Yoshida, T. and Hirai, M. (2001). Mapping of fruit shape and color development traits in eggplant (Solanum melongena L.) based on RAPD and AFLP markers. Breed. Sci. 51, 19-26.

Polignano, G., Uggenti, P., Bisignano, V. and Della Gatta, C. (2010). Genetic divergence analysis in eggplant (Solanum melongena L.) and allied species. Genet. Resour. Crop Evol. $57,171-181$.

Prohens, J., Blanca, J.M. and Nuez, F. (2005). Morphological and molecular variation in a collection of eggplants from a secondary center of diversity: implications for conservation and breeding. J. Amer. Soc. Hort. Sci. 130, 54-63.

Prohens, J., Plazas, M., Raigón, M.D., Seguí-Simarro, J.M., Stommel, J.R. and Vilanova, S. (2012). Characterization of interspecific hybrids and first backcross generations from crosses between two cultivated eggplants (Solanum melongena and S. aethiopicum Kumba group) and implications for eggplant breeding. Euphytica 186, 517-538.

Rodríguez, R., Strecker, J., Brewer, M., Gonzalo, M.J., Anderson, C., Lang, L., Sullivan, D., Wagner, E., Strecker, B., Drushal, R., Dujmovic, N., Fujimuro, K., Jack, A., Njanji, I., Thomas, J., Gray, S. and van der Knaap, E. (2010). Tomato Analyzer user manual version 3. http://www.oardc.osu.edu/vanderknaap/files/Tomato_Analyzer_3.0_Manual.pdf.

Rodríguez, G.R., Muñoz, S., Anderson, C., Sim, S.C., Michel, A., Causse, M., McSpadden Gardener, B.B., Francis, D. and van der Knaap, E. (2011). Distribution of SUN, OVATE, LC, and $F A S$ in the tomato germplasm and the relationship to fruit shape diversity. Plant Physiol. $156,275-285$.

Rodríguez, G. R., Moyseenko, J. B., Robbins, M. D., Huarachi Morejón, N., Francis, D. M., van der Knaap, E. (2010). Tomato Analyzer: A Useful Software Application to Collect 
Accurate and Detailed Morphological and Colorimetric Data from Two-dimensional Objects. J. Vis. Exp. (37), e1856, doi:10.3791/1856 (2010).

Rodríguez-Burruezo, A., Prohens, J. and Nuez, F. (2008). Performance of hybrids between local varieties of eggplant (Solanum melongena) and its relation to the mean of parents and to morphological and genetic distances among parents. Eur. J. Hort. Sci. 73, 76-83.

Tümbilen, Y., Frary, A., Mutlu, S. and Do $\square$ anlar, S. (2011). Genetic diversity in Turkish eggplant (Solanum melongena) varieties as determined by morphological and molecular analyses. Intl. Res J. Biotechnol. 2, 16-25.

Vilanova, S., Manzur, J.P. and Prohens, J. (2012). Development and characterization of genomic SSR markers in eggplant and their application to the study of diversity and relationships in a collection of different cultivar types and origins. Mol. Breed. 30, 647-660.

Wricke, G., and Weber, W. (1986). Quantitative genetics and selection in plant breeding. De Gruyter, Berlin, Germany. 